\title{
A comprehensive study on the buckling behaviour of woven composite plates with major aerospace cutouts under uniaxial loading
}

\author{
S. B. Rayhan \\ Institute of Flight Vehicle Engineering, Nanchang Hangkong University \\ 696 South Fenghe Avenue, Nanchang, China, \\ *Email: rayhan.saiaf@mail.ru \\ Phone: +86-13080933760
}

\begin{abstract}
Current research paper presents a comprehensive linear buckling study based on Finite Element Method (FEM) to investigate the effect of cutout shape and area on the buckling behaviour of E-glass woven composite plates under uniaxial loading. Considered plate has a dimension of $150 \mathrm{~mm} \times 75 \mathrm{~mm} \times 3 \mathrm{~mm}$ where loading edges are simple supported (shorter side) and other two edges are free. Major aerospace cutout shapes i.e. circular, square, elliptical (horizontal and vertical) and diamond are studied to understand their effect on plates' critical buckling load. FE code Ansys is adopted to investigate the case studies. A limited number of experimental buckling tests are also carried out and compared with the FE code results. From finite element analyses, it is found that for any cutout shape, as the cutout area increases, buckling load decreases significantly. Moreover, increasing the plate thickness by $0.5 \mathrm{~mm}$ can raise the buckling load up to $50 \%$. More importantly, fibre orientation angle has most significant effect on the critical buckling load of plates where fibre orientation aligned with loading direction can increase the plates' critical buckling load from 2.6 to 2.8 times than aligned with $90^{\circ}$. Finally, among all cutout shapes, elliptical (vertical) cutout shows better buckling results.
\end{abstract}

Keywords: Finite element method; E-glass composite plate; cutout; critical buckling.

\section{INTRODUCTION}

Composite materials are extensively used in aerospace, automobile and ship building industries for their superior mechanical properties like high stiffness, strength to weight ratios, longer fatigue life and better resistance to corrosion etc. In these thin-walled structures, cutouts are often introduced for various purposes like weight reduction, access for electrical wires, hydraulic and fuel lines, damage inspection and maintenance. However, presence of these openings can drastically reduce the stability of the structure both locally and globally. Shanmugam et al. [1] proposed a simplified formula to predict the critical buckling load in terms of opening area ratio and plate slenderness for isotropic plates. The results were found to be slightly conservative with an error of less than $10 \%$. A semi-analytical solution method is presented for the buckling analysis of orthotropic laminated plates with reinforced cutouts subjected to uniform and non-uniform compression loading. It was found that the buckling 
strength of the panel increases with the increasing thickness and radius of the cutout reinforcement [2]. Ovesy and Fazilati [3] introduced two different modeling techniques and applied to S-a (Semi analytical) as well as spline FSM (Finite Strip Method) formulations in order to investigate the buckling strength and free vibration behavior of isotropic and layered composite plates containing square and circular cutouts. They concluded that the longitudinal strip assemble approach in modeling cutouts, whilst being more accurate, is only applicable to rectangular cutout shape and can only be implemented by the spline FSM formulation. However, at the expense of some accuracy, the negative stiffness approach has the advantages of having fewer degrees of freedom, having the ability to deal with different cutout shapes as well as being suitable for both spline and S-a FSM formulations. Recently, Gong [4] presented theoretical solutions based on improved energy method to predict the helical buckling behavior of pipes in vertical, inclined and horizontal wells. He showed that the new formula can solve the Pipe-in-Pipe's (PIP) critical helical buckling forces successfully and provides a deeper insight on the PIP's helical buckling onset, as well as the post helical buckling behavior. More recently, an extended Ritz formulation for the analysis of buckling and post buckling behavior of cracked composite multi layered plate is presented where the formulation agrees quite well with the finite element simulations which confirms the accuracy and potential of the formulation [5].

Jain and Kumar [6] used finite element method to study the buckling and post buckling response of symmetric square laminates with a central circular/elliptical cutout under uniaxial compression. They concluded that ellipse aligned along the loading direction has lower buckling load than that with a corresponding circular cutout. However, a stochastic finite element method is used by Onkar et al. [7] to predict the critical buckling load of composite laminate under uniaxial and shear loading found that plates with horizontal and vertical elliptical cutouts generally show an increase in critical buckling load compared with plates with a circular cutout. Ghannadpour et al. [8] studied rectangular composite plates with circular/elliptical cutouts and Kumar and Singh [9] studied square composite plates with circular/elliptical cutouts. Both of the studies revealed that in some cases, plates with circular/elliptical cutouts may have higher buckling load than the corresponding plates without a cutout. More recently, a non-uniform edge loading on buckling characteristics of laminated composite panels with and without cutout were investigated by Rajanna et al. [10]. It was found that in most cases, the panel with larger cutout offers higher buckling resistance compared to the panel without cutouts.

Murat et al. [11] and Baba [12] investigated composite plates with U-shaped cutouts and circular and semi-circular cutouts. They found that fiber orientation angle has strong influence on plate buckling load. Moreover, numerical and experimental studies, carried out by Aktas and Balcioglu [13] on pultruded composite beams with circular cutouts revealed that buckling load can be enhanced 11 times by changing rowing orientation angle. Tercan and Aktas [14] analyzed rib knitting glass/epoxy laminated plates with cutouts where they focused on the tightness level of knitted fabrics. They found that for all cutout shapes, buckling load decreases by higher tightness level of rib knitting in glass/epoxy plates.

In order to reduce the cutout stress concentration and increase the buckling stability of composite panels, Guo et al. [15] conducted experimental and numerical analyses for shear loaded laminated and sandwich composite panels. They came to the conclusion that the most effective means of improving the buckling stability of composite panels without weight penalty is to employ sandwich design, and the most effective reinforcement for reducing 
sandwich panel stress concentration at minimum weight cost is the central tube design. Lopes et al. [16] used AFP technology to fabricate variable stiffness panels. Their research showed that it is possible to design and manufacture composite panels whose buckling and first-ply failure responses are insensitive to the existence of a central hole. Guo et al. [17] studied composite $\mathrm{C}$-section structure having circular and diamond shape cutout with flange reinforcements. They revealed that both cutout and reinforcement has little effect on the buckling stability of C-section structure. A comprehensive study carried out by Kim et al. [18] on different stiffening method on perforated plates concluded that for different loading conditions e.g. longitudinal compression, transverse compression and in plane edge shear loading doubling plate method, carling stiffener method and face plating method works better respectively.

Singh and Kumar [19] carried out FE analyses to various cutout shapes and sizes on buckling and postbuckling response of square quasi-isotropic composite laminate under uniaxial compression loading where they found that cutout reduces the buckling load of the laminate and it reduces further with increase in cutout size. Singh et al. [20] investigated thin rectangular isotropic plates with central circular cutouts subjected to partial edge compression using FEM. They found that for plates with cutouts have reduced critical buckling load compared to plates without cutouts, however, influence of various partial edge compression are almost same. Rajanna et al. [21] studied the influence of centrally placed circular and square cutouts on vibration and buckling characteristics of different ply oriented laminated panels under the action of uniaxial compression, uniaxial tension and biaxial, compression-tension loading configurations. It was found that even though the tensile buckling loads are higher than that of compressive buckling loads, it continuously reduces with the increased cutout sizes irrespective of ply orientations.

Komur and Sonmez [22] studied the elastic buckling behavior of plates with circular cutouts where the cutout location varied along the principal X-axis of plates subjected to linearly varying loading. The results show that center of a circular hole should not be placed at the end of the outer panel for all loading cases. A grooved shaped cutout panels are investigated for steel plates by Mohtaram et al. [23] found that with identical values of the groove angle $\theta$, the buckling load decreases with increasing the length of the groove, and this effect is most prominent when $\theta=90^{\circ}$. A numerical investigation was carried out by Narayana et al. [24] to study the effect of plate aspect ratio and location of the square/rectangular cutout on the buckling behavior of a sixteen ply quasi-isotropic graphite/epoxy symmetrically laminated rectangular composite plate subjected to various inplane compressive loading. Their studies revealed that cutout orientation has effect on buckling when it is located at the center. However, towards the edge, the cutout orientation has insignificant effect where no effect is observed when the cutouts move in Y-direction. Erkliğ and Yeter [25] studied various cutout shape effects on the buckling characteristics of composite plates and found that cutout orientation angle has less effect on the critical buckling load. Erkliğ et al. [26] investigated lateral buckling behavior of polymer matrix composites with circular, rectangular, square, elliptical and triangle cutouts and found that elliptical cutout is the best and square cutout is the worst. Recently, research on buckling analyses were conducted by Shariati et al. [27] on steel plates having circular cutouts. Their studies revealed that buckling load is lower than the yield load, and elastic buckling occurred in all specimens. An experimental [28] and numerical [29] research was carried out on multidirectional CFRP laminates subjected to quasi static shear loading with cutouts of three 
different forms, including circular, curved-diamond and rounded-rectangular shape. It was demonstrated that the presence of cutouts does result in a significant reduction in structural stability and structural buckling occurs far before the material failure.

From the above literature review, it was found that even though theoretical formulations of solving critical buckling loads of structures are successful [4,5] but plates with cutouts have got limitations [1-3]. Based on Finite Element formulations and experimental studies, plates with different cutout shapes [6-13, 19-29] and reinforcements [15-18] were studied but comprehensive studies based on all major cutouts are notably limited. This paper addresses the effect of all major cutout shapes (circular, square, horizontal ellipse, vertical ellipse and diamond) and sizes, plate aspect ratio, ply thickness and fiber orientation angle on the buckling behavior of E-glass composite plate.

\section{MATERIALS AND METHODS}

\section{Specimen Preparation}

Araldite LY556 and Hardener HY951 manufactured by Ciba Inc. was used as the matrix composition and E-glass fiber TEX 2400 as the reinforcing agent to prepare the woven composite laminate. A hand layup technique was adopted. In total, twelve fiber layers were glued one above another applying resin on top of each layer to form the laminate. Nominal thickness of the laminate was $3 \mathrm{~mm}$ with an approximate $44 \%$ fiber volume fraction.

In order to determine the mechanical properties of E-glass composite, tensile testing samples were prepared according to ASTM standard [30]. For critical buckling load, specimens were prepared with a dimension of $150 \mathrm{~mm}$ (length) and $75 \mathrm{~mm}$ (width). For perforated specimens, both circular and square holes were created at the center. Seven different kind of plates, without hole, with a circular hole of diameter $10 \mathrm{~mm}, 30 \mathrm{~mm}$ and $50 \mathrm{~mm}$ and with square hole of $10 \mathrm{~mm}, 30 \mathrm{~mm}$ and $50 \mathrm{~mm}$ side by side were prepared. In total, thirty-five specimens were prepared where each five similar specimens were experimented to confirm the average critical buckling load of the particular composite plate. All the specimen were prepared and tested in School of Material Science and Engineering, Nanchang Hangkong University.

\section{Experimental Setup and Material Testing}

For both tensile tests and buckling analyses, a servo Hydraulic Universal Testing Machine (MTS-CN 100) with a maximum capacity of $200 \mathrm{KN}$ was used. The mechanical properties of the E-glass composite material are given below in Table 1.

Table 1. Mechanical properties of E-glass composite material.

\begin{tabular}{cccccc}
\hline $\begin{array}{c}E_{x x} \\
(\mathrm{GPa})\end{array}$ & $\begin{array}{c}E_{y y}=E_{z z} \\
(\mathrm{GPa})\end{array}$ & $v_{x y}=v_{z x}$ & $v_{y z}$ & $\begin{array}{c}G_{x y}=G_{z x} \\
(\mathrm{GPa})\end{array}$ & $\begin{array}{c}G_{y z} \\
(\mathrm{GPa})\end{array}$ \\
\hline 49.148 & 16.870 & 0.334 & 0.114 & 2.87 & 1.5 \\
\hline
\end{tabular}


For buckling case studies, composite plates were simply supported on shorter edges and longer two edges were free. Plates were loaded slowly at $1 \mathrm{~mm} / \mathrm{min}$ rate and "lateral deflection vs load" graph was plotted by the digital computer connected with the hydraulic actuator for each case. In order to determine the critical buckling load from the graph, point of inflection was used [31].

\section{Finite Element Analysis Setup}

For numerical solutions, FE code Ansys was adopted to find the critical buckling load of the composite plates. Finite element setup is shown in Figure 1. Plate area is located on XY plane and the normal is aligned in $\mathrm{Z}$ direction. Top edge of the plate is allowed to move freely on the loading direction (y direction) and the bottom edge displacement is fixed, while only rotation $\mathrm{Z}$ is allowed. Other two unloaded edges are free. $0^{0}$ fiber orientation is aligned with the global X-axis. To find the buckling load in Ansys, a unit force is given on the top edge keeping other boundary conditions unchanged, a load multiplier will show the linear eigenvalue buckling load.

For all cases, dimensions of the plate are fixed as length, $\mathrm{L}=150 \mathrm{~mm}$, width, $\mathrm{w}=75 \mathrm{~mm}$ and thickness, $\mathrm{t}=3 \mathrm{~mm}$. All major cutouts found for aerospace applications, i.e. circular, square, diamond and elliptical (both horizontal and vertical) are considered for case studies to understand the effect of various cutouts in buckling loading. Firstly, plates with circular holes were designed with a diameter of $10 \mathrm{~mm}, 20 \mathrm{~mm}, 30 \mathrm{~mm}, 40 \mathrm{~mm}$ and $50 \mathrm{~mm}$ which are denoted as cutout area I, II, III, IV and V respectively. Then, equal amount of area were perforated from the center in form of square, diamond and ellipse (both horizontal and vertical).

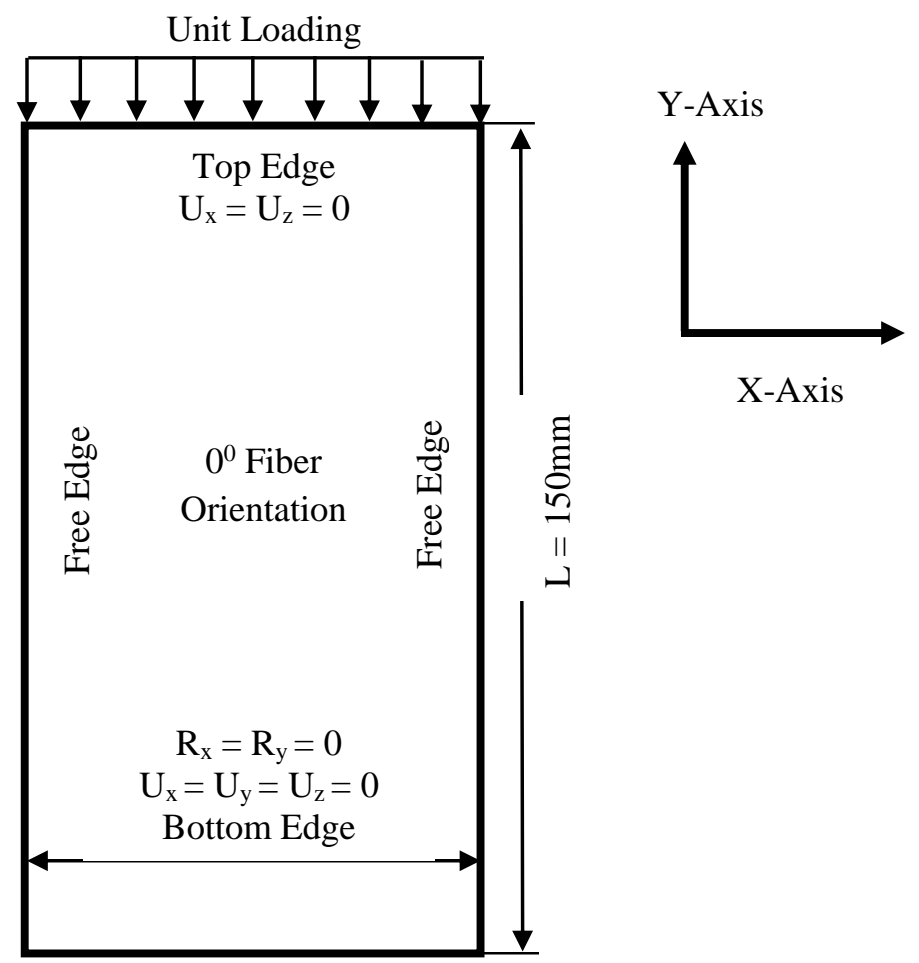

Figure 1. Plate geometry with parametric dimensions in FE. 
Even though, for different cutout shapes, we had to generate the mesh accordingly, but for all cases, face mapping with quadrilateral elements were created with optimal quality. Moreover, areas near cutout were refined to determine more accurate results as for finite element analyses, these areas are sensitive. Example of meshed bodies are shown in Figure 2.

\section{RESULTS AND DISCUSSION}

Firstly, we compared the numerical buckling results with experimental findings, Table 2 . The concurrence between experimental and analytical buckling results is within about $23 \%$ error. The maximum deviation is found to be $23.3 \%$ for $10 \mathrm{~mm} \times 10 \mathrm{~mm}$ square cutout. Since the FEA results are based on idealized geometry, loading conditions, boundary conditions, uniform thickness distribution and nominal material properties, they are not very close to experimental results [12]. In addition, percentage difference among experimental results can reach up to $15.1 \%$ for non-perforated plates, $8.8 \%$ for plates with $10 \mathrm{~mm}$ circular cutouts, $10.6 \%$ for plates with $30 \mathrm{~mm}$ circular cutouts, $15.7 \%$ for plates with $50 \mathrm{~mm}$ circular cutouts, $11 \%$ for plates with $10 \mathrm{~mm} \times 10 \mathrm{~mm}$ square cutouts, $6.5 \%$ for plates with $30 \mathrm{~mm} \times 30 \mathrm{~mm}$ square cutouts and $12.6 \%$ for plates with $50 \mathrm{~mm} \times 50 \mathrm{~mm}$ square cutouts.

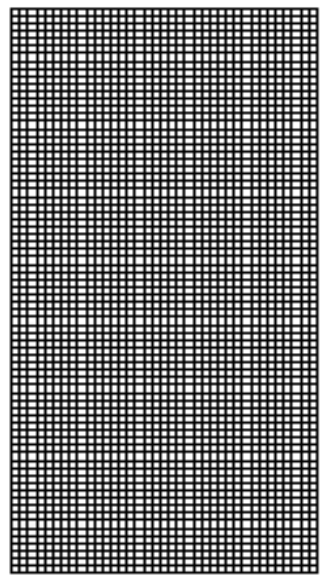

(a)

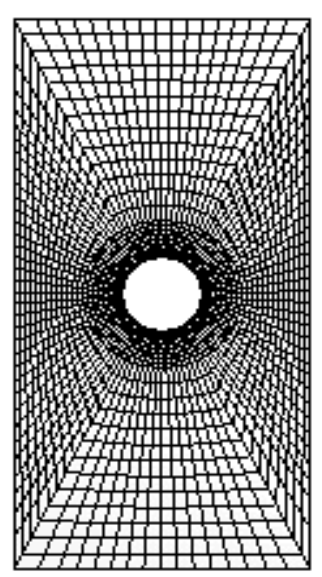

(b)

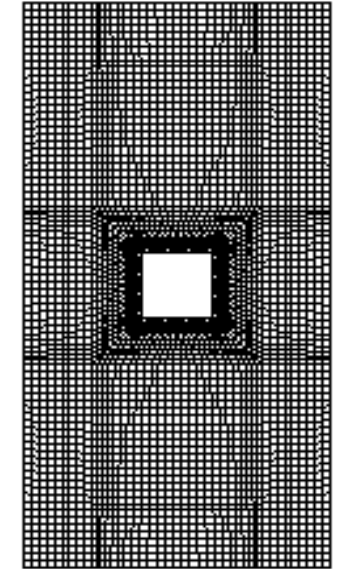

(c) 


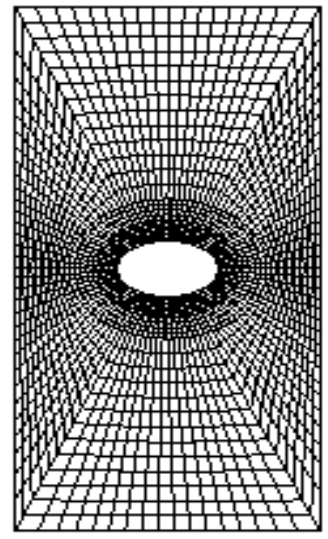

(d)

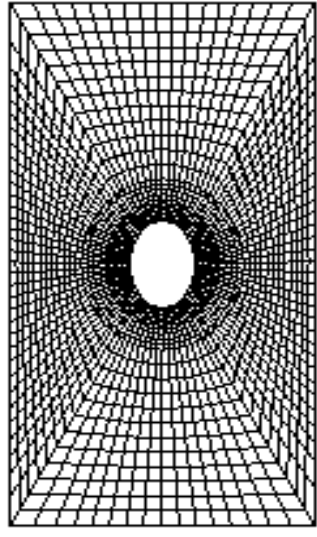

(e)

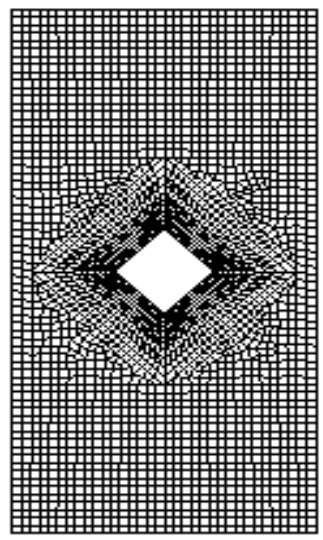

(f)

Figure 2. Meshed bodies of non-perforated and various perforated plates: (a) Nonperforated plate, (b) plate with circular cutout, (c) plate with rectangular cutout, (d) plate with elliptical cutout (horizontal), (e) plate with elliptical cutout (vertical) and (f) plate with diamond cutout.

\section{Effect of the Plate Aspect Ratio}

Effect of the plate aspect ratio on the critical buckling load of plates is illustrated in Figure 3. In general, buckling load of the plate decreases with the increase of the plate aspect ratio. 
Table 2. Experimental and numerical buckling results.

\begin{tabular}{|c|c|c|c|c|c|}
\hline Plate Type & $\begin{array}{c}\text { Specimen } \\
\text { No. }\end{array}$ & $\begin{array}{c}\text { Experimental } \\
\text { Critical } \\
\text { Buckling } \\
\text { Load }[\mathrm{N}]\end{array}$ & $\begin{array}{c}\text { Average } \\
\text { Critical } \\
\text { Buckling } \\
\text { Load [N], } \\
\text { Experimental }\end{array}$ & $\begin{array}{c}\text { FEA } \\
\text { Critical } \\
\text { Buckling } \\
\text { Load }[\mathrm{N}]\end{array}$ & $\begin{array}{c}\text { Deviation } \\
\%, \\
\text { between } \\
\text { Avg. } \\
\text { Critical } \\
\text { and FEA }\end{array}$ \\
\hline \multirow{5}{*}{$\begin{array}{l}\text { Non- } \\
\text { perforated } \\
\text { Plate }\end{array}$} & I & 2712 & \multirow{5}{*}{2952} & \multirow{5}{*}{2431.6} & \multirow{5}{*}{17.6} \\
\hline & II & 3156 & & & \\
\hline & III & 2908 & & & \\
\hline & IV & 3077 & & & \\
\hline & $\mathrm{V}$ & 2908 & & & \\
\hline \multirow{5}{*}{$\begin{array}{l}\text { Circular } \\
\text { Cutout, } \\
10 \mathrm{~mm} \\
\text { Diameter }\end{array}$} & I & 2178 & \multirow{5}{*}{2227} & \multirow{5}{*}{2334.9} & \multirow{5}{*}{4.4} \\
\hline & II & 2325 & & & \\
\hline & III & 2325 & & & \\
\hline & IV & 2129 & & & \\
\hline & $\mathrm{V}$ & 2178 & & & \\
\hline \multirow{5}{*}{$\begin{array}{l}\text { Circular } \\
\text { Cutout, } \\
30 \mathrm{~mm} \\
\text { Diameter }\end{array}$} & I & 2374 & \multirow{5}{*}{2296} & \multirow{5}{*}{2008} & \multirow{5}{*}{12.5} \\
\hline & II & 2423 & & & \\
\hline & III & 2179 & & & \\
\hline & IV & 2325 & & & \\
\hline & $\mathrm{V}$ & 2178 & & & \\
\hline \multirow{5}{*}{$\begin{array}{l}\text { Circular } \\
\text { Cutout, } \\
50 \mathrm{~mm} \\
\text { Diameter }\end{array}$} & I & 1344 & \multirow{5}{*}{1226} & \multirow{5}{*}{1500.9} & \multirow{5}{*}{22.3} \\
\hline & II & 1148 & & & \\
\hline & III & 1197 & & & \\
\hline & IV & 1197 & & & \\
\hline & $\mathrm{V}$ & 1246 & & & \\
\hline \multirow{5}{*}{$\begin{array}{c}\text { Square } \\
\text { Cutout, } \\
10 \mathrm{~mm} \times 10 \\
\mathrm{~mm}\end{array}$} & I & 1829 & \multirow{5}{*}{1770} & \multirow{5}{*}{2182.5} & \multirow{5}{*}{23.3} \\
\hline & II & 1682 & & & \\
\hline & III & 1879 & & & \\
\hline & IV & 1731 & & & \\
\hline & $\mathrm{V}$ & 1731 & & & \\
\hline \multirow{5}{*}{$\begin{array}{c}\text { Square } \\
\text { Cutout, } \\
30 \mathrm{~mm} \times 30 \\
\mathrm{~mm}\end{array}$} & I & 1587 & \multirow{5}{*}{1535} & \multirow{5}{*}{1880.3} & \multirow{5}{*}{22.5} \\
\hline & II & 1486 & & & \\
\hline & III & 1535 & & & \\
\hline & IV & 1584 & & & \\
\hline & $\mathrm{V}$ & 1487 & & & \\
\hline \multirow{5}{*}{$\begin{array}{c}\text { Square } \\
\text { Cutout, } \\
50 \mathrm{~mm} \times 50 \\
\mathrm{~mm}\end{array}$} & I & 1241 & \multirow{5}{*}{1153} & \multirow{5}{*}{1396.6} & \multirow{5}{*}{21.7} \\
\hline & II & 1094 & & & \\
\hline & III & 1143 & & & \\
\hline & IV & 1094 & & & \\
\hline & $\mathrm{V}$ & 1192 & & & \\
\hline
\end{tabular}


In addition, it is found that for all cutout areas, cutout shape has strong influence on critical buckling load when the plate aspect ratio is 1. For instance, for cutout area III, square cutout has $8 \%$ higher buckling load than diamond cutout and around $61 \%$ higher buckling load than circular and elliptical (vertical) cutouts. But this influence starts to decrease as the plate aspect ratio increases.

\section{Effect of the Plate Thickness}

Figure 4 shows the effect of plate thickness i.e. ply number on the critical buckling load of plates. It can be seen that the buckling load of the plate increases with the thickness of the plate. More importantly, an increase of $0.5 \mathrm{~mm}$ thickness can provide $50 \%$ higher buckling load which becomes almost $120 \%$ for an increase of $1 \mathrm{~mm}$ and this trend is identical for all cutout areas and shapes. In addition, for all cutout areas, elliptical (vertical) cutout shows highest buckling load while diamond cutouts are being the lowest.

\section{Effect of the Fiber Orientation Angle}

The effect of fiber orientation angle has been illustrated for all cutout areas in Figure 5. For our case studies, $0^{0}$ fiber orientation is perpendicular to the loading direction. As the fiber orientation changes from $0^{0}$ to $30^{\circ}$, a decrease of buckling load is observed, around $21 \%$ $22 \%$, which is the lowest among all the fiber direction considered for our case studies. From $60^{\circ}$ orientation, buckling load starts to increase and $90^{\circ}$ fiber orientation (aligned with the loading direction) shows almost 2.6 - 2.8 times higher buckling load than $0^{0}$ fiber orientation. In addition, for cutout area I and II, for all fiber orientation angles, elliptical (vertical) cutout shows highest buckling load but this trend changes for other cutout areas. For cutout area III, IV and V, only for $0^{0}$ fiber orientation case, elliptical (vertical) cutout shows highest buckling load, but for all other orientations, circular cutout performs better.

\section{Effect of the Cutout Area and Shape}

Effect of cutout area and shape on plates' critical buckling load is shown in Figure 6 and Figure 7. From Figure 6, it is apparent that for any cutout shape, the buckling load decreases with the increase of the cutout area. Moreover, it is found that among all major cutouts, elliptical (vertical) cutout shows maximum critical buckling load. However, both circular and elliptical (vertical) cutouts have identical buckling load values where the difference never exceeds more than $3.8 \%$. But, for diamond cutout areas, this difference is highest, starts from $5.9 \%$ which reaches up to $29.1 \%$. Figure 7 shows the loss percentage of critical buckling load for all major cutouts. It is observed that among all major cutout shapes, elliptical (vertical) cutout losses from $3.31 \%$ to $35.94 \%$ buckling stability as the cutout area increases which is the least, where diamond cutout losses from 8.7 to $50 \%$ which is the highest among all the analyzed shapes. 


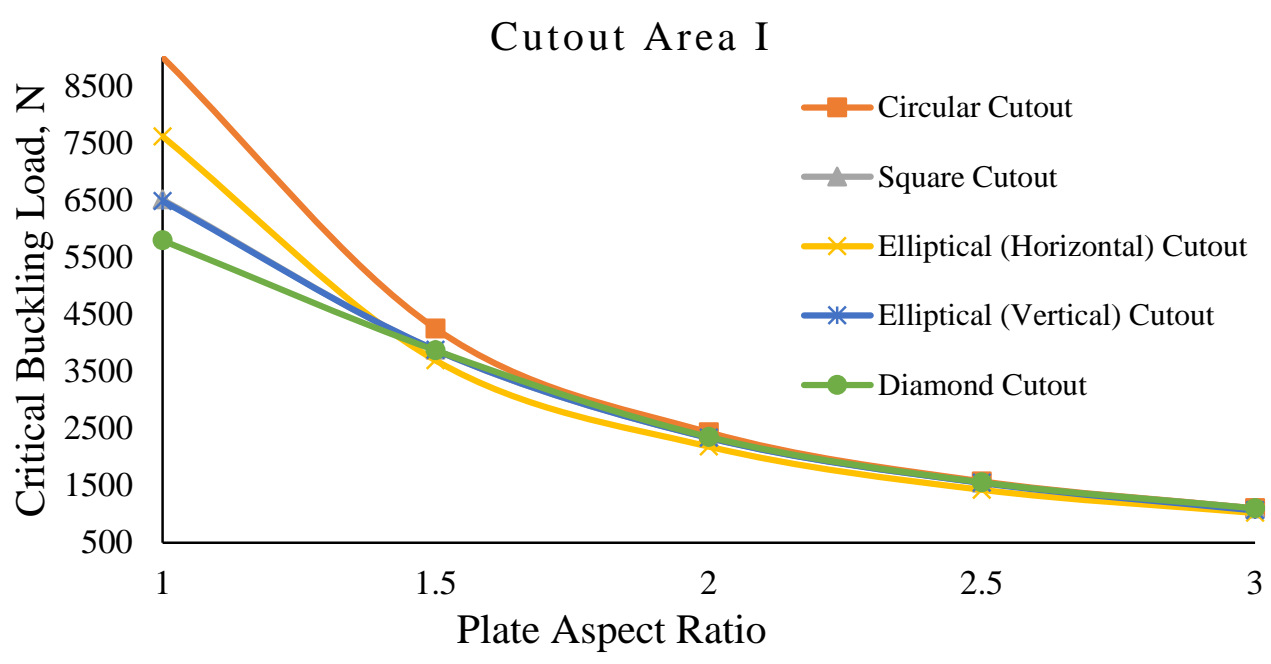

(a) Plate Aspect Ratio Vs Critical Buckling Load, Cutout Area I

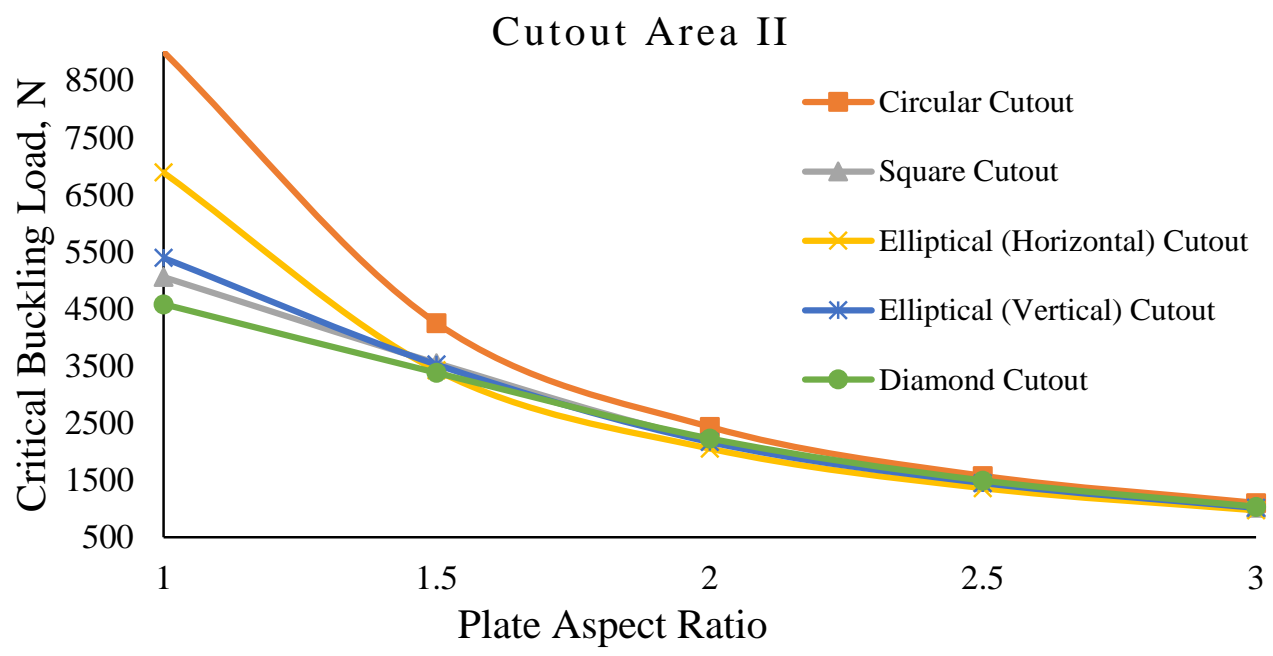

(b) Plate Aspect Ratio Vs Critical Buckling Load, Cutout Area II 


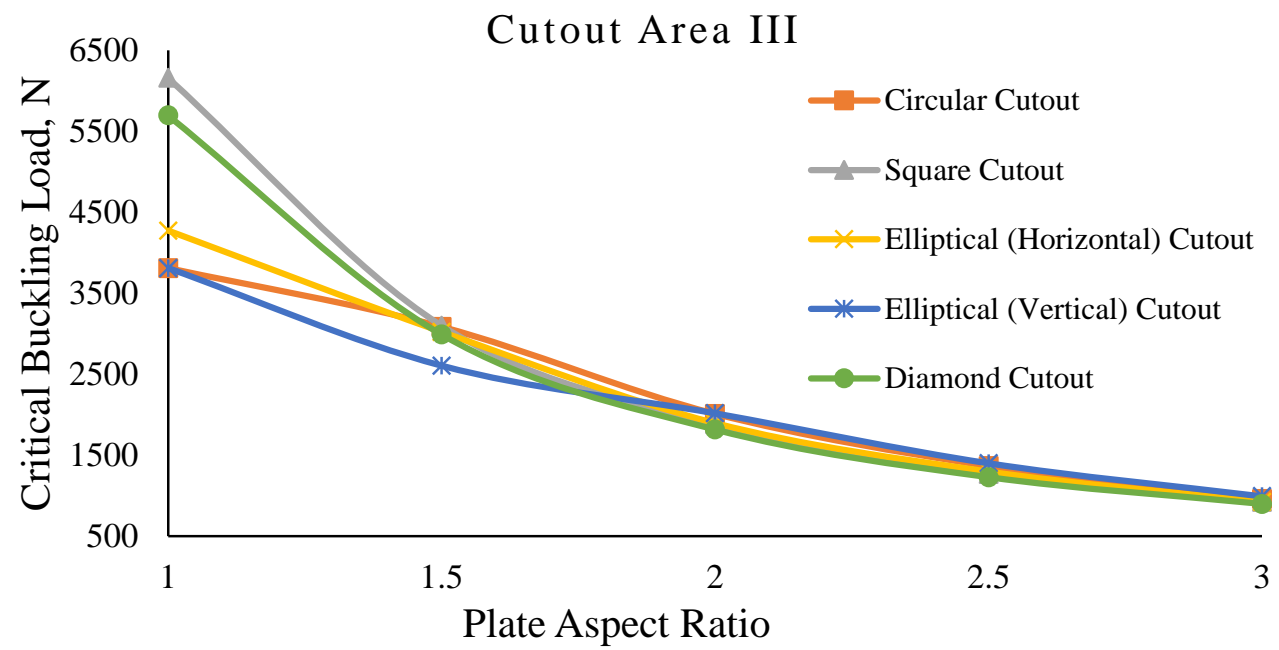

(c) Plate Aspect Ratio Vs Critical Buckling Load, Cutout Area III

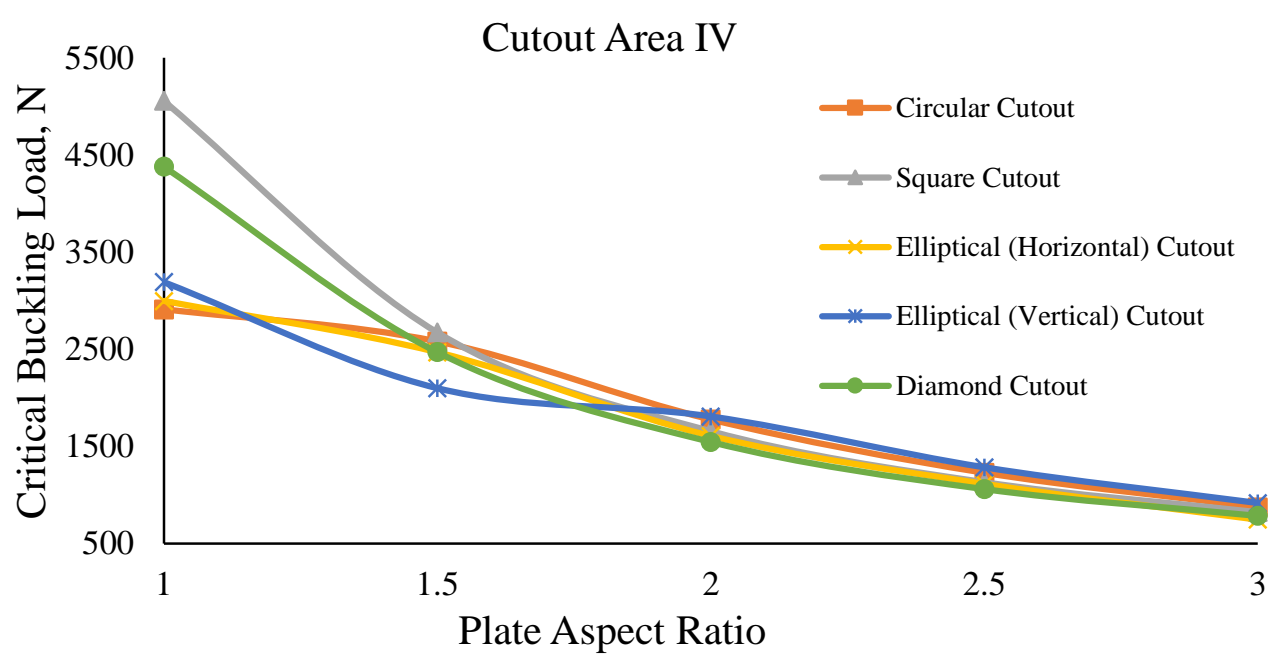

(d) Plate Aspect Ratio Vs Critical Buckling Load, Cutout Area IV 


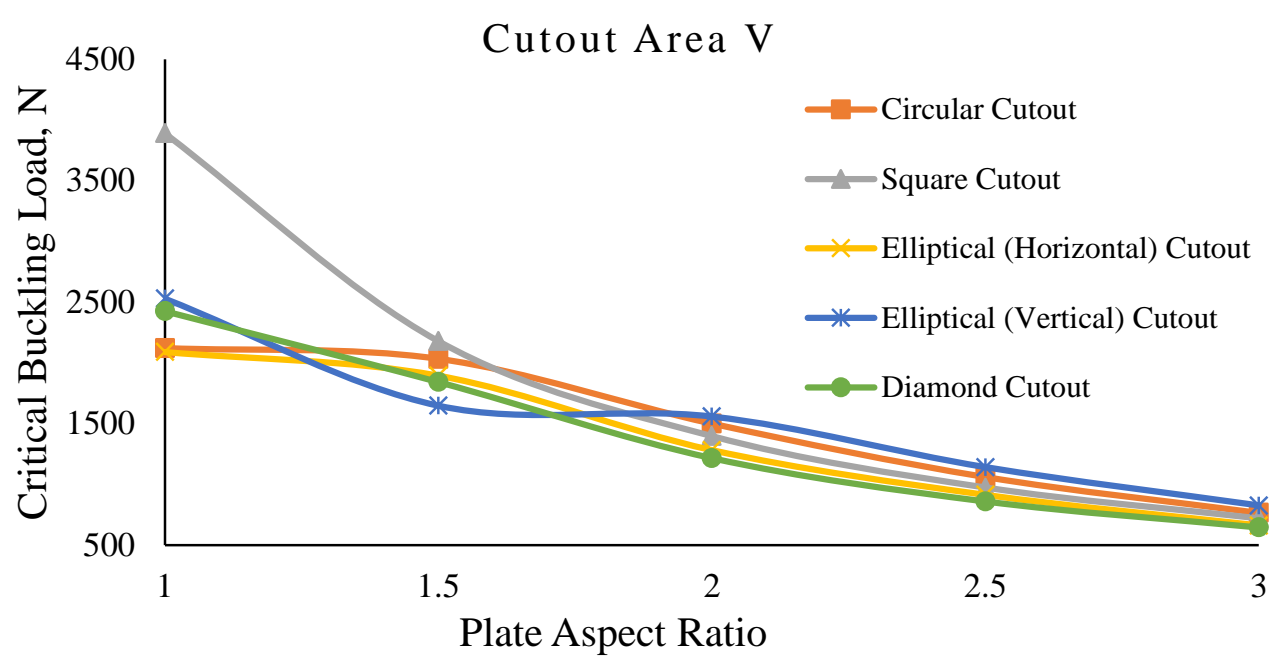

(e) Plate Aspect Ratio Vs Critical Buckling Load, Cutout Area V

Figure 3. Effect of the plate aspect ratio on critical buckling load

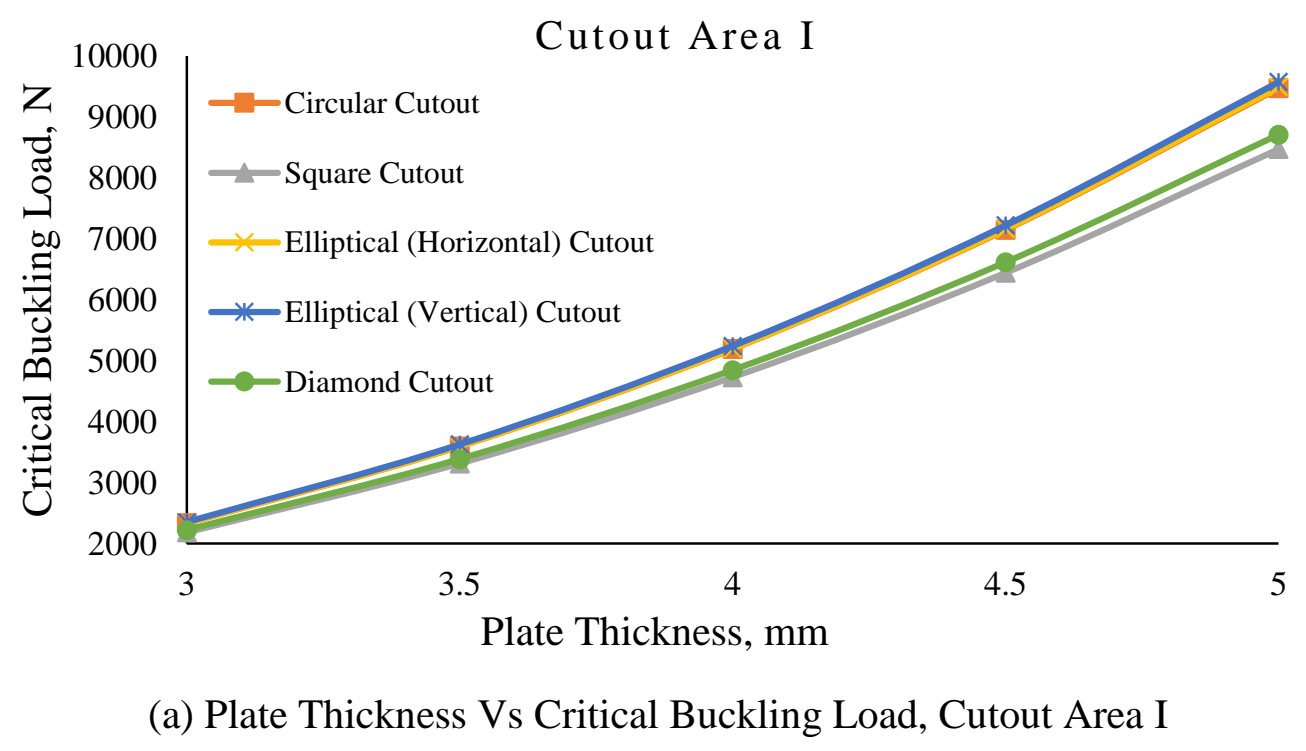




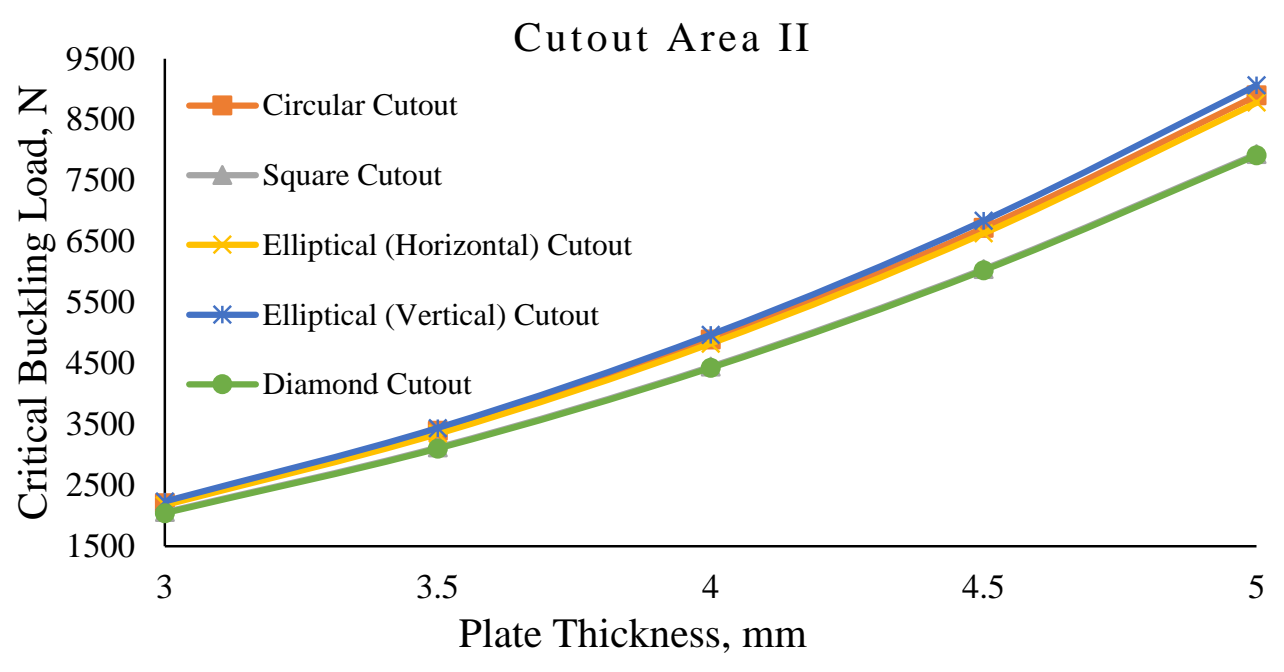

(b) Plate Thickness Vs Critical Buckling Load, Cutout Area II

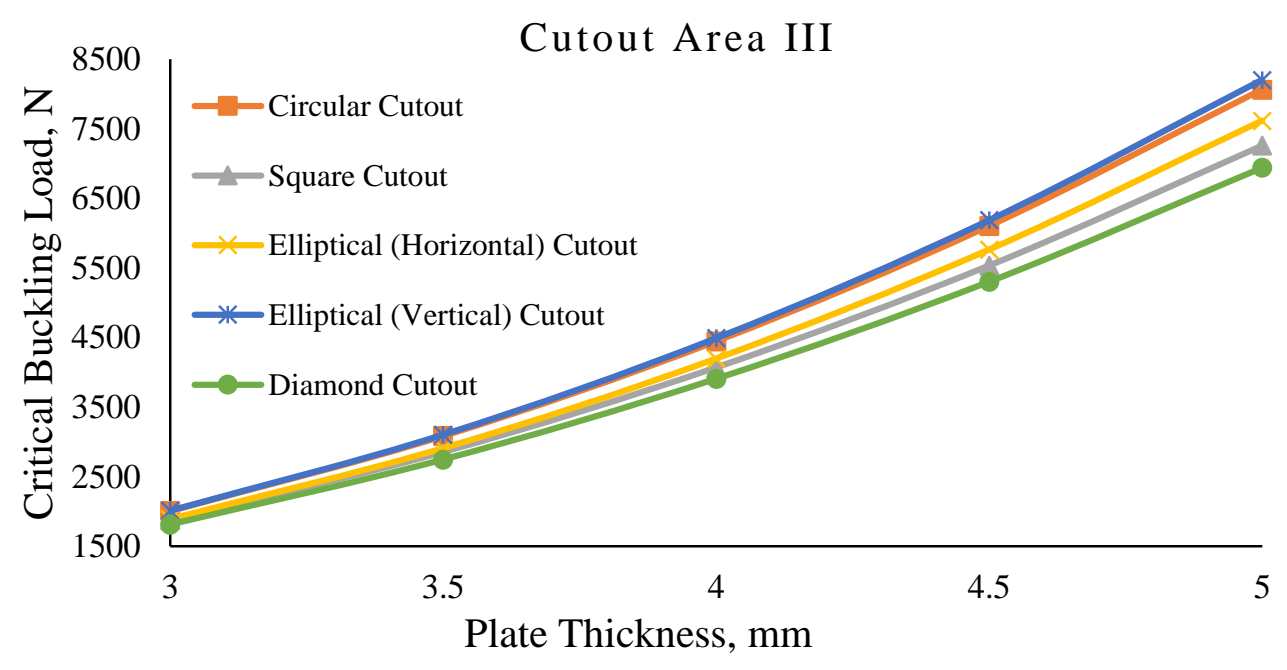

(c) Plate Thickness Vs Critical Buckling Load, Cutout Area III 


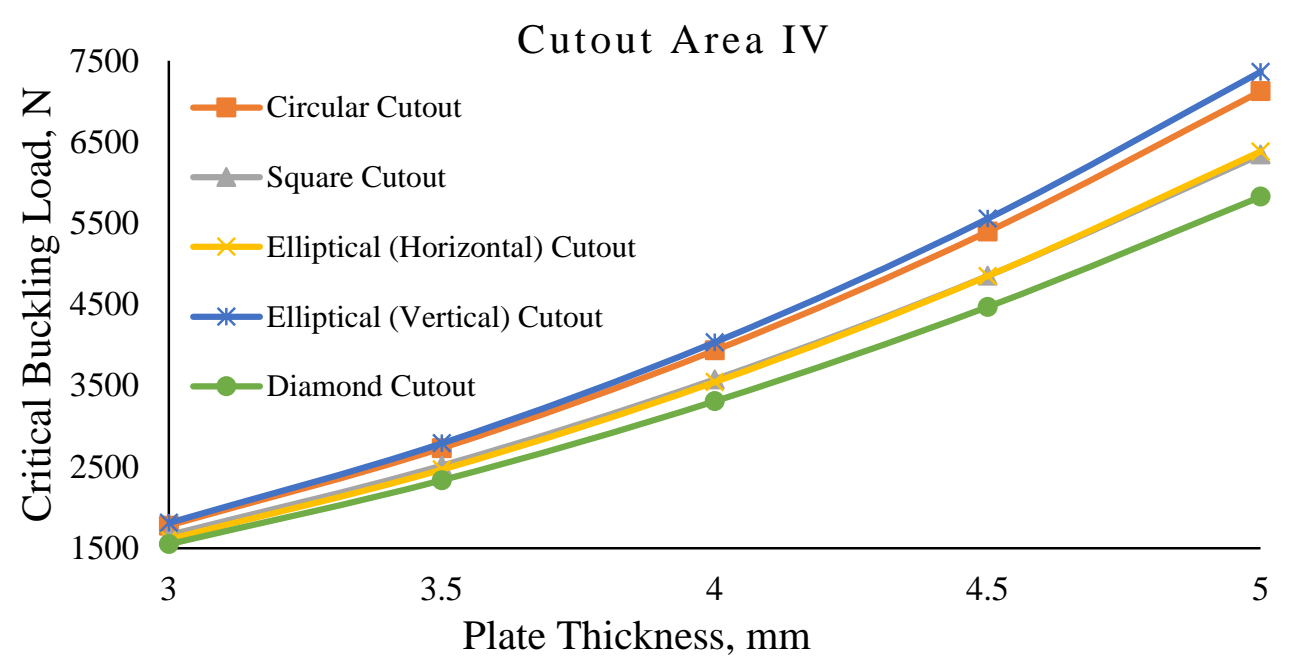

(d) Plate Thickness Vs Critical Buckling Load, Cutout Area IV

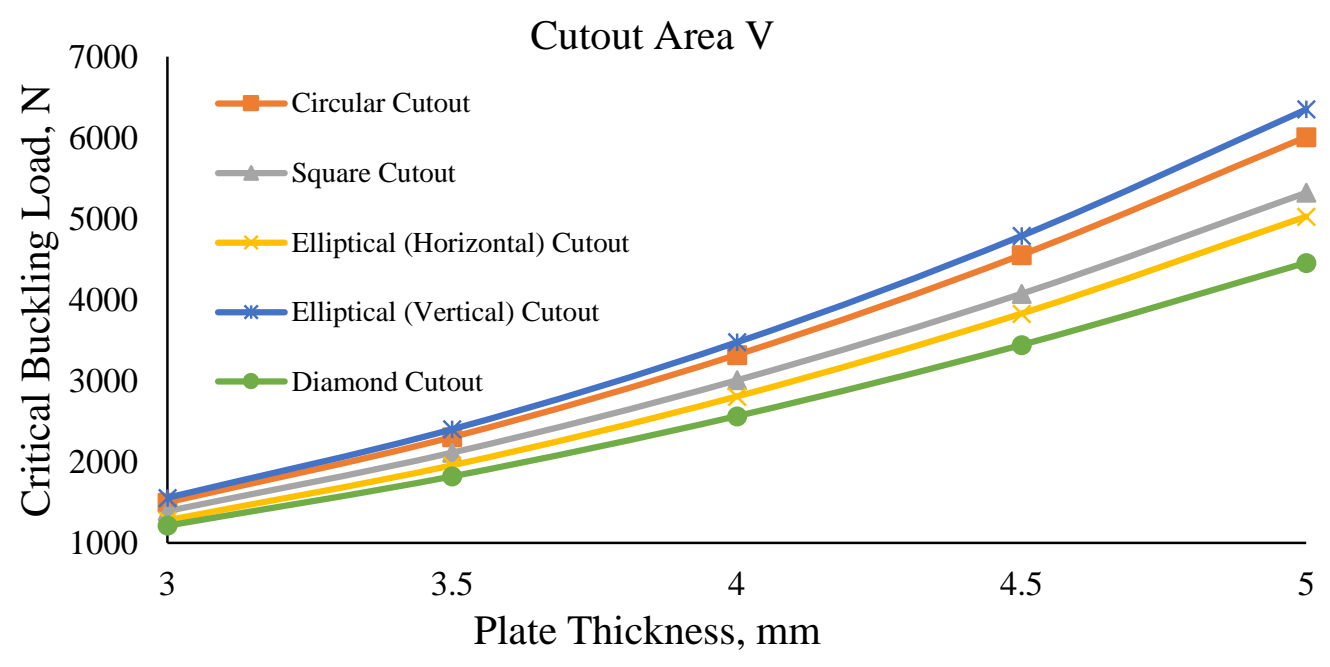

(e) Plate Thickness Vs Critical Buckling Load, Cutout Area V

Figure 4. Effect of the plate thickness on the critical buckling load. 


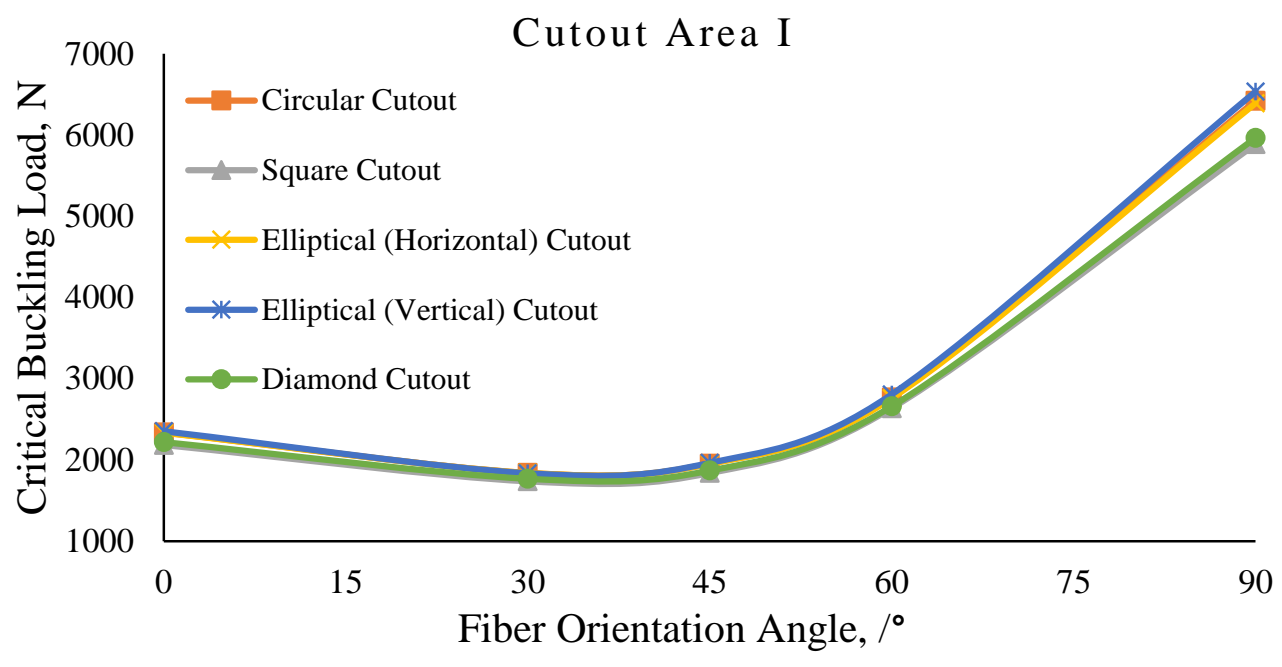

(a) Fibre Orientation Angle Vs Critical Buckling Load, Cutout Area I

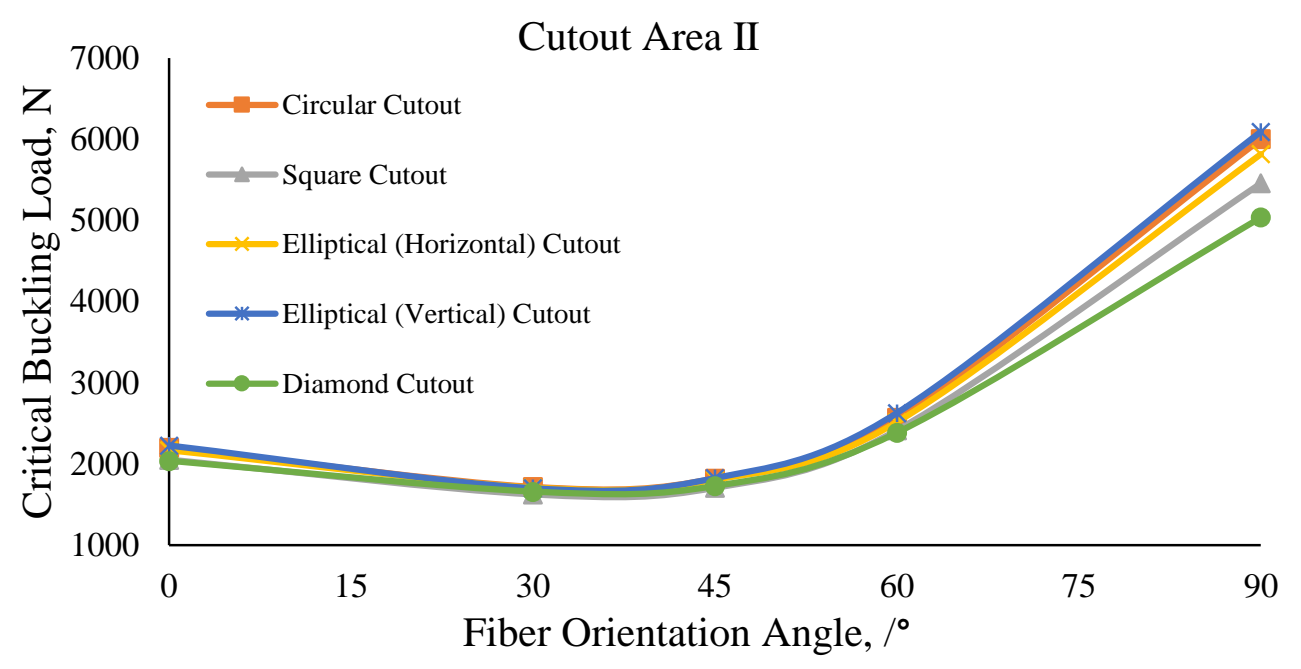

(b) Fibre Orientation Angle Vs Critical Buckling Load, Cutout Area II 


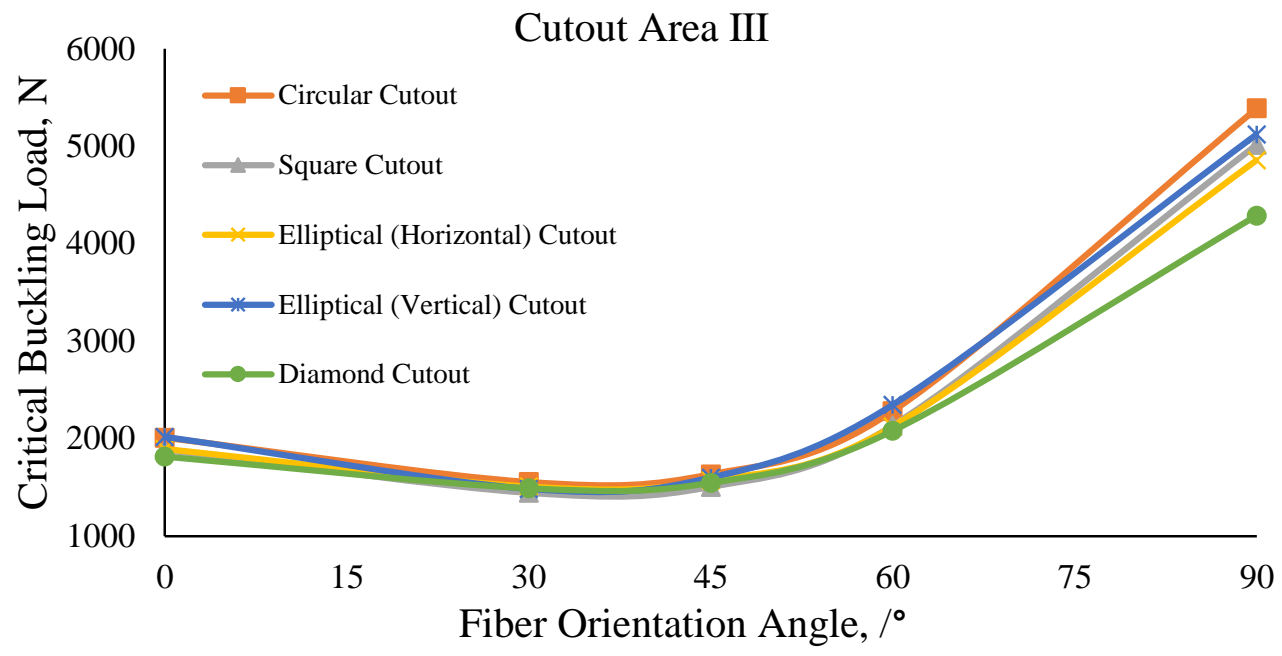

(c) Fibre Orientation Angle Vs Critical Buckling Load, Cutout Area III

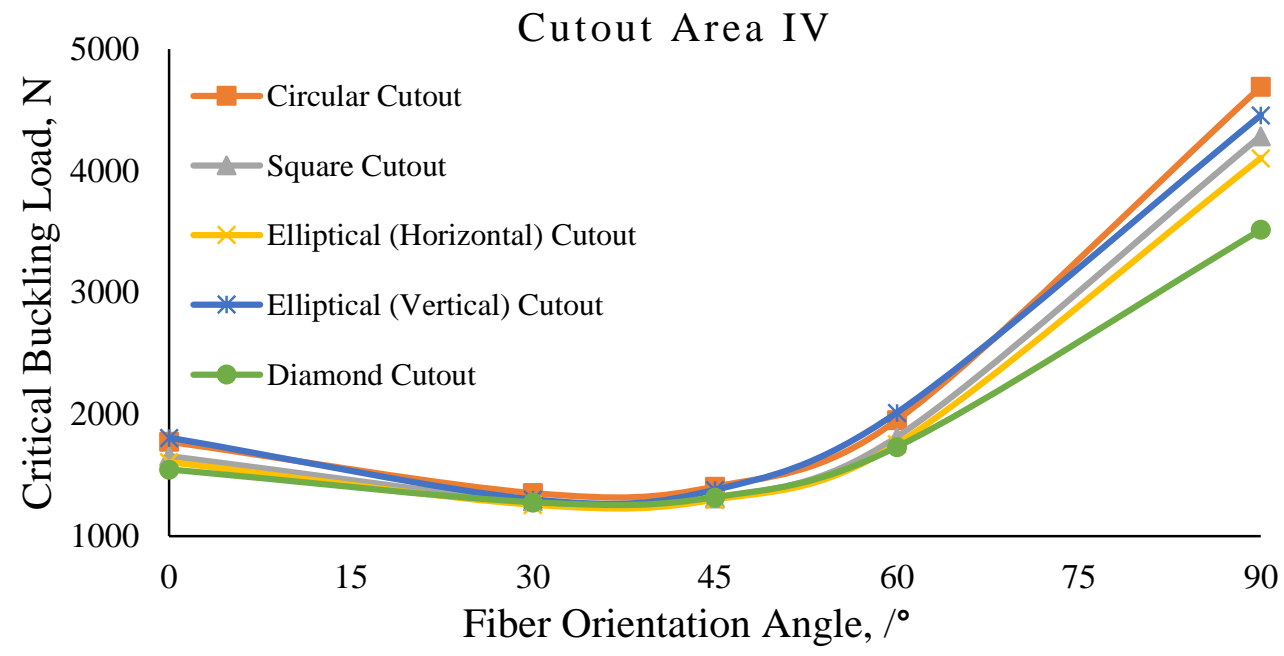

(d) Fibre Orientation Angle Vs Critical Buckling Load, Cutout Area IV 


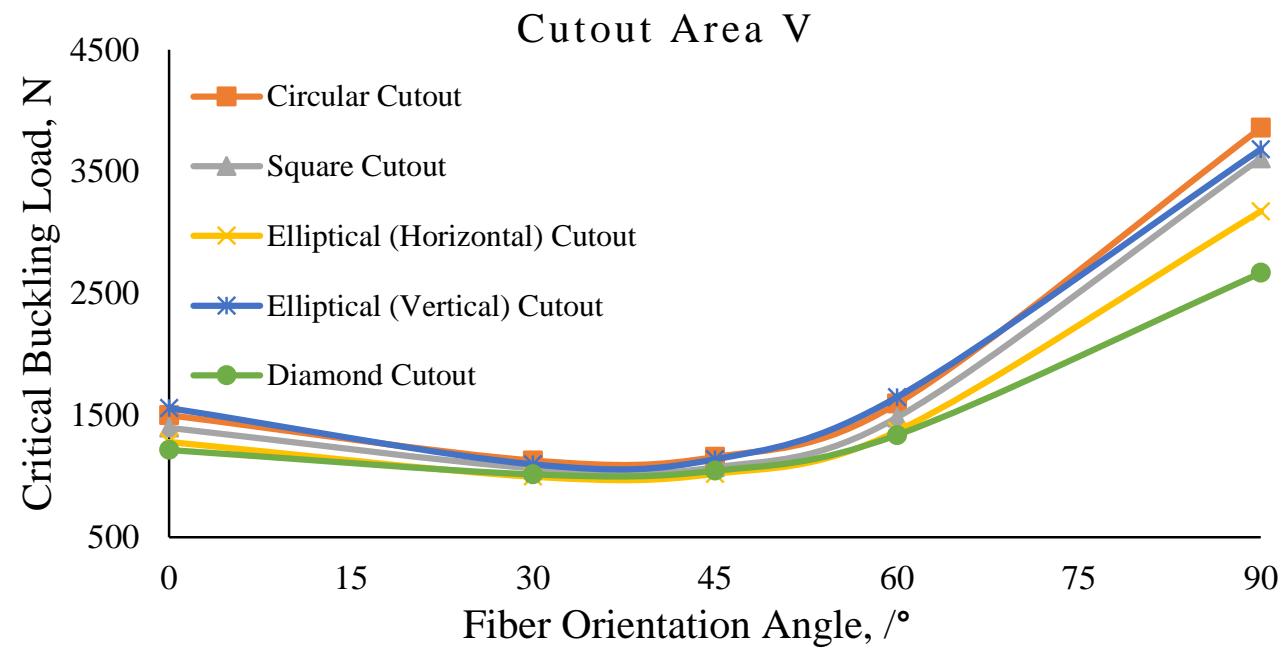

(e) Fibre Orientation Angle Vs Critical Buckling Load, Cutout Area V

Figure 5. Effect of fibre orientation angle on the critical buckling load.

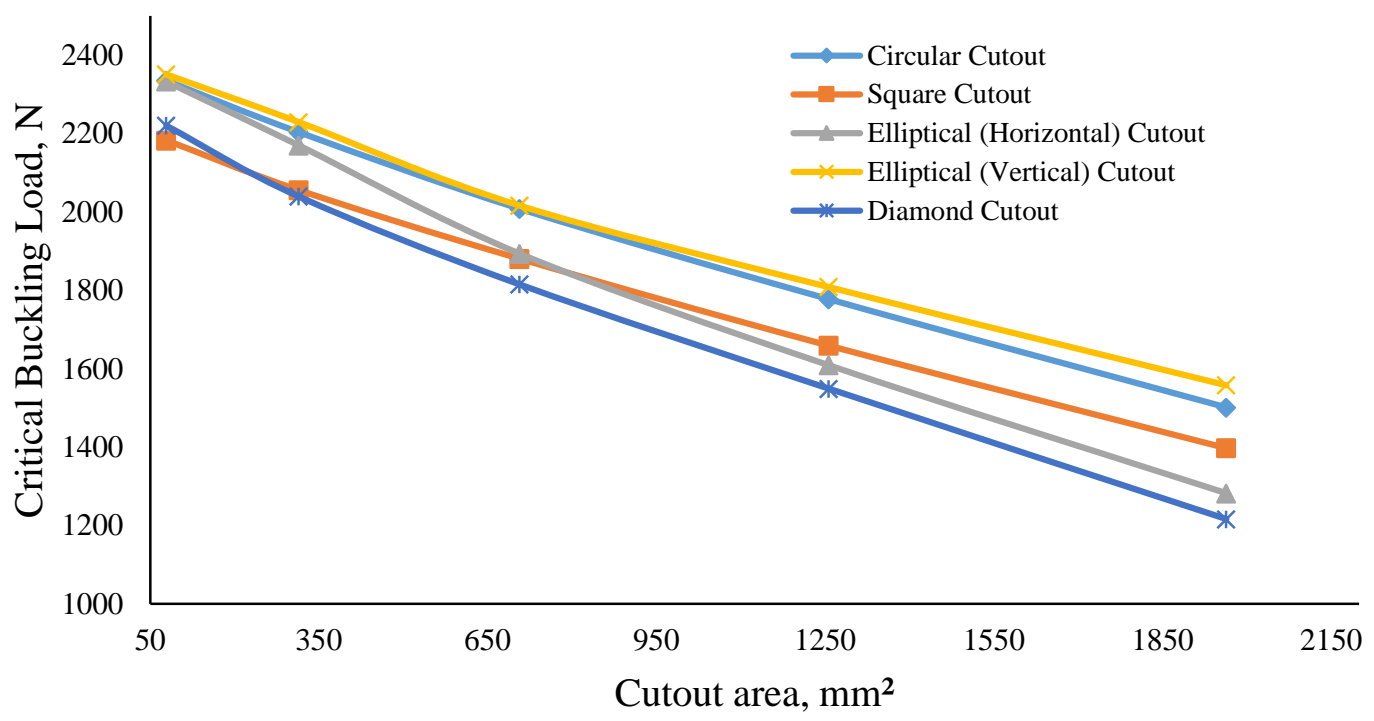

Figure 6. Cutout area against critical buckling load. 


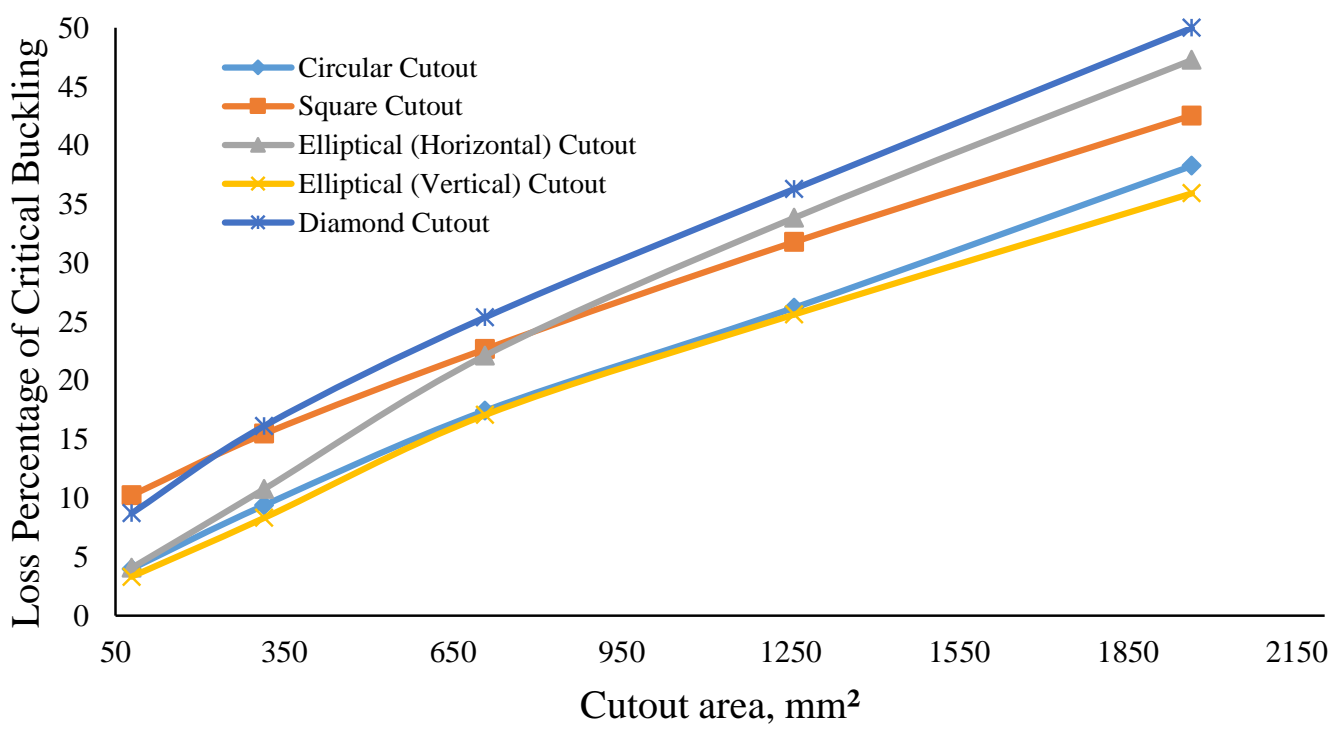

Figure 7. Cutout area against loss percentage of critical buckling load.

\section{CONCLUSION}

Finite element analyses were performed to investigate the critical buckling load of E-glass woven composite plates with major aerospace cutout shapes i.e. circular, square, elliptical (both horizontal and vertical) and diamond. Other parametric studies like plate aspect ratio, plate thickness and fibre orientation angle were also investigated. Based on the carried out research following conclusions can be made.

1. Cutout shape has strong effect on the plates with aspect ratio 1. However, as the aspect ratio of the plate increases, effect of the shape on critical buckling load of the plates decreases.

2. Critical buckling load of the plate decreases with the increase of the plate aspect ratio.

3. A slight increase of the thickness can significantly raise the critical buckling load of the plates.

4. Fibre orientation angle affects most to the critical buckling load of the plates. If the loading direction and fibre orientation angle is aligned, then highest buckling load can be achieved which is 2.6 to 2.8 times higher than $90^{\circ}$ oriented cases. However, $30^{\circ}$ orientation has shown the least critical buckling load which starts to increase from $60^{0}$ orientation.

5. For all cutout shapes, with the increase of the cutout area buckling load decreases significantly. This can be up to $50 \%$ for diamond cutout. However, among all cutout shapes, elliptical (vertical) cutout shows better buckling results.

In addition, FEA results of square and circular cutouts were compared with experimental values where the maximum deviation is found to be $23.3 \%$ for $10 \mathrm{~mm} \times 10 \mathrm{~mm}$ square cutout. Since the numerical results are limited to linear buckling analyses which are based on idealized geometry, loading conditions, boundary conditions, uniform thickness and nominal material properties, they are not very close to the experiments. However, in future, we wish 
to continue our research on non-linear buckling analyses of composite plates based on geometrical imperfection which may answer the large discrepancy between FEA and experimental results.

\section{ACKNOWLEDGEMENTS}

The author would like to thank Professor Yu Chunjin of Institute of Flight Vehicle Engineering, Nanchang Hangkong University to provide experimental data in collaboration with School of Materials Science and Engineering, Nanchang Hangkong University.

\section{REFERENCES}

[1] Shanmugam N, Thevendran V, Tan Y. Design formula for axially compressed perforated plates. Thin-Walled Structures. 1999;34(1):1-20.

[2] Oterkus E, Barut A, Madenci E. Buckling of Composite Plates with a Reinforced Circular Cutout Subjected to Uniform and Non-Uniform Compression. 45th AIAA/ASME/ASCE/AHS/ASC Structures, Structural Dynamics \&amp; Materials Conference. 2004.

[3] Ovesy H, Fazilati J. Buckling and free vibration finite strip analysis of composite plates with cutout based on two different modeling approaches. Composite Structures. 2012;94(3):1250-1258.

[4] Gong L. Onset and Post Buckling of Pipe-in-Pipe's Helical Buckling Using Improved Energy Method. Proceedings of the 37th International Conference on Ocean, Offshore and Arctic Engineering. 2018.

[5] Milazzo A, Benedetti I, Gulizzi V. An extended Ritz formulation for buckling and post-buckling analysis of cracked multilayered plates. Composite Structures 2018;201:980-994.

[6] Jain P, Kumar A. Postbuckling response of square laminates with a central circular/elliptical cutout. Composite Structures. 2004;65(2):179-185.

[7] Onkar A, Upadhyay C, Yadav D. Stochastic Buckling Analysis of Laminated Plates Under Shear and Compression. AIAA Journal. 2007;45(8):2005-2014.

[8] Ghannadpour S, Najafi A, Mohammadi B. On the buckling behavior of cross-ply laminated composite plates due to circular/elliptical cutouts. Composite Structures. 2006;75(1-4):3-6.

[9] Kumar D, Singh S. Effects of boundary conditions on buckling and postbuckling responses of composite laminate with various shaped cutouts. Composite Structures. 2010;92(3):769-779.

[10] Rajanna T, Banerjee S, Desai Y, Prabhakara D. Effect of boundary conditions and non-uniform edge loads on buckling characteristics of laminated composite panels with and without cutout. International Journal for Computational Methods in Engineering Science and Mechanics. 2017;18(1):64-76.

[11] Yazici M, Ozcan R, Ulku S, Okur I. Buckling of Composite Plates with U-Shaped Cutouts. Journal of Composite Materials. 2003;37(24):2179-2195.

[12] Baba B. Buckling Response of Rectangular Laminated Composite Plates with Cutouts. Science and Engineering of Composite Materials. 2007;14(1). 
[13] Aktas M, Balcioglu H. Buckling behavior of pultruded composite beams with circular cutouts. Steel and Composite Structures. 2014;17(4):359-370.

[14] Tercan M, Aktaş M. Buckling behavior of $1 \times 1$ rib knitting laminated plates with cutouts. Composite Structures. 2009;89(2):245-252.

[15] Guo S, Zhou L, Cheung C. Cutout reinforcements for shear loaded laminate and sandwich composite panels. International Journal of Mechanics and Materials in Design. 2007;4(2):157-171.

[16] Lopes C, Gürdal Z, Camanho P. Tailoring for strength of composite steered-fibre panels with cutouts. Composites Part A: Applied Science and Manufacturing. 2010;41(12):1760-1767.

[17] Guo S, Li D, Zhang X, Xiang J. Buckling and post-buckling of a composite C-section with cutout and flange reinforcement. Composites Part B: Engineering. 2014;60:119124.

[18] Kim J, Jeon J, Park J, Seo H, Ahn H, Lee J. Effect of reinforcement on buckling and ultimate strength of perforated plates. International Journal of Mechanical Sciences. 2015;92:194-205.

[19] Singh S, Kumar D. Cutout shape and size effects on response of quasi-isotropic composite laminate under uni-axial compression. Structural Engineering and Mechanics. 2010;35(3):335-348.

[20] Singh S, Kulkarni K, Pandey R, Singh H. Buckling analysis of thin rectangular plates with cutouts subjected to partial edge compression using FEM. Journal of Engineering, Design and Technology. 2012;10(1):128-142.

[21] Rajanna T, Banerjee S, Desai Y, Prabhakara D. Vibration and buckling analyses of laminated panels with and without cutouts under compressive and tensile edge loads. Steel and Composite Structures. 2016;21(1):37-55.

[22] Aydin Komur M, Sonmez M. Elastic buckling of rectangular plates under linearly varying in-plane normal load with a circular cutout. Mechanical Research Communication 2008;35(6):361-371.

[23] Mohtaram Y, Kahnamouei J, Shariati M, Behjat B. Experimental and numerical investigation of buckling in rectangular steel plates with groove-shaped cutouts. Journal of Zhejiang University SCIENCE A. 2012;13(6):469-480.

[24] Narayana A, Rao K, Kumar R. Effect of location of cutout and plate aspect ratio on buckling strength of rectangular composite plate with square/rectangular cutout subjected to various linearly varying in-plane loading using FEM. International Journal of Mechanics. 2013;7(4):508-517.

[25] Erkliğ A, Yeter E. The effects of cutouts on buckling behavior of composite plates. Science and Engineering of Composite Materials. 2012;19(3).

[26] Erkliğ A, Yeter E, Bulut M. The effects of cut-outs on lateral buckling behavior of laminated composite beams. Composite Structures. 2013;104:54-59.

[27] Shariati M, Faradjian Y, Mehrabi H. Numerical and Experimental Study of Buckling of Rectangular Steel Plates with a Cutout. Journal of Solid Mechanics, 2016;8(1):116-129.

[28] Li X, Gao W, Liu W. The bearing behavior and failure characteristic of CFRP laminate with cutout under shearing load: Part I. Experiments. Composite Structures. 2016;141:355-365. 
[29] Li X, Gao W, Liu W. The bearing behavior and failure characteristic of CFRP laminate with cutout under shearing load: Part II. Numerical simulations. Composite Structures. 2016;141:366-374.

[30] Standard Test Method for Tensile Properties of Polymer Matrix Composite Materials. West Conshohocken, Pa.: ASTM International; 2014.

[31] Buskell N, Davies G, Stevens K. Postbuckling Failure of Composite Panels. Composite Structures. 1985;3:290-314. 